\title{
"SOBRE LA FORMA PRIMERA Y LA MATERIA PRIMERA» DE AVEMPACE
}

\author{
Introducción, traducción y notas de \\ Charif Dandachli Zohbi y Pilar Zaldivar Bouthelier \\ Sección de Árabe, Instituto de Idiomas, Universidad de Zaragoza
}

\section{RESUMEN}

En este trabajo presentamos la traducción al castellano đel tratado «Sobre la forma primera y la materia primera» del filósofo zaragozano Avempace, precedida por una introducción que trata de mostrar los cauces por los que ha llegado hasta nosotros esta obra y los problemas que presenta para la traducción.

Palabras clave: Forma primera, materia primera, elementos, rango y grado.

\section{ABSTRACT}

The aim of this essay is to offer the Spanish translation of the "Treatise on Primary Form and Primary Matter" written by the philosopher Avempace, from Saragossa. The preceding introduction is an attempt to show the ways through which this work has reached us and the difficulties it presents for its translation.

Key words: Primary form, Primary matter, Elements, Rank and Grade.

\section{INTRODUCCIÓN}

Con objeto de centrar el contexto de esta traducción, antes de exponerla, queremos hacer un breve recorrido por los listados y manuscritos que se conservan de las obras de Avempace $^{1}$.

En primer lugar, y por lo que respecta a las listas conocemos dos:

1. Una ofrecida por sù contemporáneo y amigo Ibn al-Imām que está contenida en el manuscrito de Oxford ${ }^{2}$.

2. Y otra compuesta por Ibn Abī Ușaybi'a que forma parte de su libro Tabaqāt alAtibb $\bar{a}^{3}$.

1 Para todo lo relacionado con los listados de las obras de Avempace, los manuscritos, y su cronología ver Avempace. El régimen del solitario. Introducción, traducción y notas de Joaquín Lomba. Madrid. 1997. Págs. 20-30.

2 Maŷmu'āt min kalām al-Sayyid al-Imām al-Jayl al-Fādill al-Wazìr Abī Bakr Muhammad Ibn Bāŷŷa al-Andalusī.

3 Ibn Abī Ușaybi 'a. Tabaqãt al-aṭibbä’'. El Cairo. 1882. 
Los contenidos de cada una de ellas difieren ya que la segunda contiene siete obras más que la primera $y$, además, hay varios títulos que no coinciden plenamente. No obstante, ninguno de estos dos listados recoge noticia alguna del tratado que ahora presentamos.

Por lo que se refiere a los manuscritos conservados son ocho: el de Oxford, el de Berlín, el de El Escorial, el de El Cairo, el de Taškent, el de Estambul, el de Sayyid 'Abd al-Razzāq al-Hasanī de Bagdad y el de Marruecos.

Las obras que contienen sólo coinciden parcialmente con los listados anteriores ya que también hay títulos que están alterados y hay algunos tratados (como el que nos ocupa) que aparecen en los manuscritos pero no en los listados.

El tratado que nosotros presentamos a continuación aparece en el manuscrito de Oxford. En lo que se refiere a su autoría hay dudas ya que, tradicionalmente, se venía considerando que era una copia realizada por al-Hasan Ibn al-Nadirir al-Adỉb del texto que el discípulo y amigo de Avempace, Ibn al-Imām, había redactado bajo su supervisión, lo cual le confería un valor especial.

Sin embargo, el manuscrito se refiere a al-Adīb como si ya hubiera muerto, lo que ha llevado a pensar que el manuscrito que actualmente conservamos no es sino la copia de la copia del original de Ibn al-Imām supervisado por Avempace.

'Alawĩ sugiere que el autor de esta segunda copia pudiera ser Muhammad Ibn al-Balādurī ya que el manuscrito se refiere a él como su autor. ${ }^{4}$

Además, 'Alawĩ advierte que este último copista dice que nuestro tratado no le ha llegado a través de la copia de al-Adīb, sino de otro lugar'. Con lo que las dudas sobre el proceso de trasmisión de este tratado quedan todavía pendientes.

En cuanto a sus publicaciones, sólo ha sido editado en árabe por 'Alawī', y sobre la base de ese trabajo hemos hecho nuestra traducción.

El texto en sí mismo presenta para la edición y la traducción dificultades de dos tipos:

1. Por un lado, las que se derivan del complicado estilo del propio autor y que dan lugar a algunos fragmentos difíciles de interpretar y que, en apariencia, no tienen sentido.

2. Y, por otro, las que se achacan al estado del manuscrito que, en algunos puntos, está ilegible.

Para solventar estos obstáculos hemos adoptadò las soluciones que ofrece 'Alawī, señalando que el texto que aparece entre ( ) es añadido o corrección que él propone a lo que no se lee bien en el original que él manejó; el que aparece entre $<>$ corresponde a partes del texto cuya supresión propone por sobrar o carecer de sentido en ese contexto; y, por último, para contribuir a la mejor comprensión del texto en castellano, hemos realizado algunos añadidos que vienen indicados entre //.

Sin más, vamos a dar paso al texto en el que Avempace se ocupa del problema de la forma y la materia primeras: qué son, cómo se relacionan entre sí y con las demás materias y formas.

4 'Alawī. Mū' allafát Ibn Bāŷŷa. Casablanca. 1987. págs. 43-46.

5 'Alawi. Rasā'il falsafiyya li-Ibn Bāŷya. Casablanca-Beirut. 1987. pág 31 y 103 nota 1.

6 'Alawī. Rasā'il falsafiyya li-Ibn Bāŷŷa. Casablanca-Beirut. 1987. págs. 103-105. 


\section{TRADUCCIÓN}

Y también de su discurso

Y éstas son las últimas palabras entre el sabio y el visir que se encontraron. ${ }^{7}$

(Sobre la forma primera y la materia primera)

Que Dios guarde al más respetable visir la gloria y la bondad que le fueron otorgadas y las verdades que le fueron procuradas por la ciencia.

Advertí en lo que mencionó ${ }^{8}$ sobre la esencia de la forma primera que unas veces parece que es una forma para los elementos, y otras parece que es otra cosa cuyo grado con respecto a las demás formas es el mismo que el grado de la materia primera con respecto a las demás materias.

Y lo que me pareció es que la forma primera es la forma simple, o las formas simples, y que ella es la que informa y se ubica en la materia que no tiene forma, cual es la materia primera. Y la forma primera es la primera forma que se actualiza en la materia <pues es la forma con la que está en la materia> además la materia primera no tiene materia para sí misma como se demostró al final del primer tratado del Libro de la Física.

Y la forma primera que se actualiza en la materia primera es la forma de los elementos, porque los elementos son seres simples, su materia es simple y su forma es simple. Esto es del Libro de la generación y la corrupción y del Libro sobre los meteorológicos y del Libro de los cielos y el mundo. Pero lo más claro es del Libro de la generación y la corrupción.

La forma siempre acompaña a la materia en la existencia, pues no hay ninguna forma que sea próxima o remota más que en la materia que le acompaña y que tiene su grado y su rango. La materia primera le acompaña /a la forma/ en la existencia pues no hay una materia próxima o remota que no le acompañe una forma para que exista en su grado y en su rango. $<y$ el rango y el grado y la forma primera $>$ Y cada materia, excepto la materia primera aunque esté lejana, es una materia para la que sólo está prescrito un ser debido a la forma que hay en ella, pues aquella forma llegó a estar preparada para aceptar la forma de aquel ser prescrito. Y la distancia que hay del rango y grado (de la materia primera) con respecto a aquella materia receptora de la forma de aquel ser (es la misma) que hay entre el rango y grado de la forma primera y la forma (de la materia receptora) de aquel ser prescrito. Pues ciertamente las formas y las materias se acompañan mutuamente, pues cuando (se eleva una cierta materia) ${ }^{9}$ un grado por una forma que se actualiza en ella, también se eleva la forma (y en la misma) proporción. Pues ciertamente la distancia que hay entre una materia prescrita y la materia primera es la misma distancia que hay entre (la forma) de aquella materia y las formas primeras en su grado $\mathrm{y}$ en su rango.

Por ejemplo:

La jarra primero es el cobre, después el polvo de /este/ mineral, luego los elementos, luego la materia primera. Pues la materia primera con respecto a la materia de la jarra está en el rango y grado cuarto como también la forma de aquella jarra primero es la forma de la jarra característica de ella, luego la forma del cobre, luego la forma del mineral en polvo que se convirtió en mineral en polvo preparado para ser cobre, pues la forma de los elementos que es la forma primera está en la lejanía y el rango cuarto. Pues la forma primera se describe como la forma de los elementos y se describe que su rango con respecto a las /demás/ formas es el mismo rango que el de la materia primera con respecto a las demás materias.

7 Estas son palabras del copista. Se refiere, obviamente, a Avempace (el sabio) y a su discípulo Ibn al-Imām (el visir).

8 Se refiere al Tratado Primero del Libro de la Física de Aristóteles, al que luego hará alusión.

9 En este punto, en el texto árabe de 'Alawĩ aparece « sideramos que carece de sentido. 
(Duda: Puesto que se ha probado que la materia y la forma primeras no son generables ni corruptibles, y que se hacen materia y forma en acto, y que todo lo dotado de una materia y una forma es un cuerpo determinado ${ }^{10}$ y que no fue aquella materia y forma /que hay/ en la materia de los elementos y, en conjunto, no tiene nada que ver con las materias generables y corruptibles, entonces ¿qué son la materia y forma primeras que se realizan en acto?, ¿y por qué se dijo de esta materia primera común que es débil ${ }^{11}$ ?)

Charif Dandachli Zohbi

Pilar Zaldívar Bouthelier

Sección de Árabe

Instituto de Idiomas

Universidad de Zaragoza

C/ Pedro Cerbuna, s/n. 50009 Zaragoza

E-mail: charif@unizar.es - zaldivar@unizar.es

10 El texto dice literalmente: que se indica hacia él con una señal.

11 Este último párrafo es confuso y, especialmente, lo es esta última palabra que el editor propone sustituir por otra que podríamos traducir como "materia prima". 